\title{
Ecological and Hydrological Changes and Interactions After Recent Comprehensive Control Projects in the Heihe River Basin
}

\author{
Mingguo $\mathrm{Ma}^{1, *}$, Xiaoli $\mathrm{Hu}^{2}$, Jianhua Wang ${ }^{2}$, and Jian Zhou ${ }^{2}$ \\ ${ }^{1}$ Heihe Remote Sensing Experimental Research Station, Cold and Arid Regions Environmental and Engineering Research \\ Institute, Chinese Academy of Sciences, Lanzhou, China \\ ${ }^{2}$ Cold and Arid Regions Environmental and Engineering Research Institute, Chinese Academy of Sciences, Lanzhou, China
}

Received 23 August 2013, revised 2 January 2014, accepted 6 January 2014

\begin{abstract}
The Heihe River Basin (HRB) is the second largest inland river basin in the northwestern arid and semi-arid regions of China. Recent Comprehensive Control Projects in the HRB were implemented beginning in 2001. The ecological and hydrological benefits of this effort were evaluated by analyzing the resulting changes in the vegetation cover and groundwater levels. Ten-year time series VEGETATION data were used to monitor the changes in vegetation cover in the HRB. The driving factors were analyzed for different regions with increasing or decreasing vegetation cover. Increases in mountainous precipitation and runoff resulted in increasing vegetation cover. In some regions in the middle and downstream portions of the HRB, decreases in vegetation cover exhibited a strong relationship with changes in groundwater levels. Constructive suggestions are provided for local governments based on the analysis results.
\end{abstract}

Key words: Ecological remote sensing, Hydrological remote sensing, Heihe River Basin, Vegetation cover change

Citation: Ma, M., X. Hu, J. Wang, and J. Zhou, 2015: Ecological and hydrological changes and interactions after Recent Comprehensive Control Projects in the Heihe River Basin. Terr. Atmos. Ocean. Sci., 26, 219-225, doi: 10.3319/TAO.2014.01.06.01(EOSI)

\section{INTRODUCTION}

The Heihe River Basin (HRB) is the second largest inland river basin in the northwestern arid and semi-arid regions of China ( $\mathrm{Li}$ et al. 2001). In the middle of the basin, the Zhangye Plain Oasis has abundant land and sunlight resources and a long cultivation history, with a relatively wealthy economy and dense population (Lu et al. 2003). Agricultural production uses a great deal of water resources through channel and well irrigation in the Zhangye Oasis. Therefore, the Zhangye Oasis is the region in the basin with the greatest consumption of water resources, which is the dominant factor affecting the hydrologic cycle and processes in this river basin (Huang 2013). In the late twentieth century the water quantity delivered downstream decreased each year. As a result, two tail-end lakes became dry throughout the year in the downstream area of the Ejin Banner. A large area of Populus euphratica forest died and the grassland began the desertification process (Ma and Veroustraete 2006a).

To reverse the increasing degradation of the natural en-

\footnotetext{
* Corresponding author

E-mail:mmg@lzb.ac.cn
}

vironment and promote desert-oasis ecological restoration in the Ejin Banner, the central government approved and began implementation of Recent Comprehensive Control Projects for the HRB beginning in 2001. This planning included water conservation engineering and administrative management reform to ensure a downstream water quantity of $9.5 \times 10^{8} \mathrm{~m}^{3}$ as the annual mean available water resource. The main measures include water saving reform in irrigation areas, reasonable allocation of water resources, adjustment of crop structures and so on. The aim is to both ensure sustainable agriculture development in the middle stream and conservative water usage of the downstream ecological restoration. As a result, the water amount transferred from the channels in the middle stream decreased 0.536 billion cubic meters. The total investment in this project is 1.538 billion RMB (Wang et al. 2008).

The downstream ecological condition clearly improved following this plan execution (Jia et al. 2011). The groundwater table and salinity increased significantly in most of the down streams with spatial heterogeneity (Wang et al. 2011). One of the tail-end lakes, East Juyan Lake, has remained 
inundated since 2005 and reaches a maximum area of approximately $40 \mathrm{~km}^{2}$ (Chang et al. 2011). In contrast, some local regions in the Zhangye Oasis appear to be experiencing ecological degradation and decreasing groundwater levels, which are also of concern. Even though some studies focused on the ecological processes or hydrological processes in the upper streams (Wu 2011), middle streams (Zhou et al. 2009), down steams (Chang et al. 2011; Jia et al. 2011; Wang et al. 2011), we still need promote integrated analysis work on the ecological and hydrological processes and their interaction in the whole river basin.

A long satellite time-series remote sensing data with a coarse spatial resolution were used in this study to monitor the changes in vegetation cover. Middle and high spatial resolution images were used to monitor the changes in land use. The climatic and hydrological changes were analyzed based on observational data from meteorological stations, hydrological stations and groundwater observation wells. There were three objectives of this study: to objectively estimate the effects of the Recent Comprehensive Control Projects in the HRB, analyze the natural and anthropogenic causes of the ecological and hydrological changes and provide scientific references for the governments for future projects in the HRB.

\section{METHODOLOGIES}

\subsection{Site Description}

The HRB, $97^{\circ} 24^{\prime}-102^{\circ} 08^{\prime} \mathrm{E}$ and $37^{\circ} 44^{\prime}-42^{\circ} 42^{\prime} \mathrm{N}$ covers an area of approximately $128900 \mathrm{~km}^{2}$. Geographic differentiation in the basin is evident. From south to north, there are three major geomorphologic units in the basin: the southern Qilian Mountains, the middle Hexi Corridor and the northern Alxa High Plain (Li et al. 2001). The HRB is composed of different ecosystems, including mountains, oasis and desert, each with individual, interacting properties. A map of the study area can be found in Ma and Veroustraete (2006a).

There are two important hydrological sections along the main stem of the Heihe River, Yingluoxia, and Zhengyixia, which divide the HRB into three parts (Fig. 1). The upstream is the area above the Yingluoxia hydrological section $\left(100^{\circ} 10.85^{\prime}, 38^{\circ} 48.46^{\prime}\right)$. The downstream is below the Zhengyixia hydrological section $\left(99^{\circ} 27.35^{\prime}, 39^{\circ} 49.43^{\prime}\right)$. The middle stream is between these two hydrological sections. The mountainous regions with their specific vertical zonation are the water sources for the entire river basin. The Hexi Corridor, located in the arid region, has an annual mean sunshine duration of 3000 - 4000 hours. Hence, the artificial oases are dominated by irrigated farmland. In the lower part of the basin the natural oases are dominated by salinized meadows, which are relatively small, fragmented and easily disturbed. Because of these other conditions in the basin the Comprehensive Control Projects in the HRB were performed primarily along the main stem.

\subsection{Data and Pre-Processing}

The VGT-S10 products are focused on strictly operational and scientific uses (Maisongrande et al. 2004). The ten-day composite VGT-S10 data with $1 \times 1 \mathrm{~km}^{2}$ spatial resolution were downloaded from the Free VEGETATION products website (http://free.VGT.vito.be).

Because of frequently unstable weather conditions, many values will occur in VGT NDVI data that are not useful within the context of vegetation monitoring. Hence, a reconstructed time series of NDVI data is necessary, representing only clear sky conditions. In this paper, we used the mean-value iteration (MVI) filter to remove the bulk of non-useful pixel data from the VGT NDVI datasets (Ma and Veroustraete 2006b).

Sixteen Landsat TM/ETM images were acquired for land use classification to analyze the changes in land use. The land use data from two periods (2000 and 2011) were extracted using the artificial interpretation method.

The meteorological data were collected from six stations by downloading the data from the China Meteorological Data Sharing Service System (http://cdc.cma.gov.cn). The mountainous regions in the upstream include Qilian, Tuole, Yeniugou. The middle stream includes Zhangye, Gaotai and the downstream is Ejin Banner (Fig. 1). The data include annual average temperature and total precipitation for 1982 through 2009. The hydrological section data were collected from two key stations, namely, Yingluoxia and

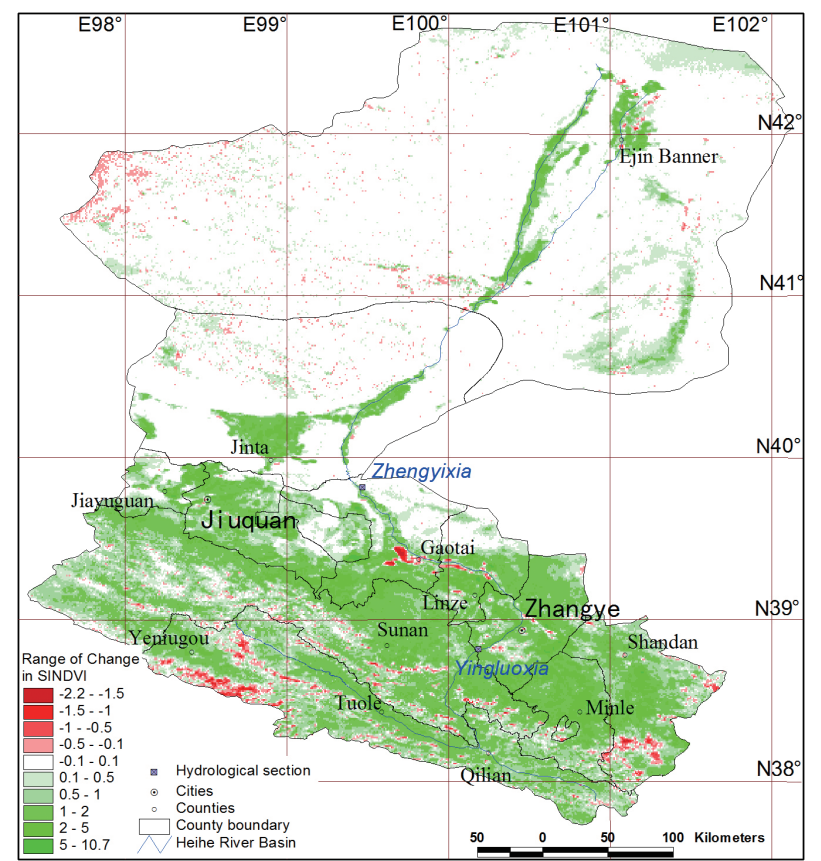

Fig. 1. The changes in vegetation cover in $2001-2010$ based on the VGT data. 
Zhengyixia. The data were provided by the Hydrology and Water Resources Bureau of Gansu Province. The groundwater data from 43 observation wells in the middle portion of the HRB from 2001 - 2010 were provided by the Second Hydro-Geological and Engineering Geology Team, Gansu Bureau of Geology and Mineral Exploitation and Development. The groundwater data from 14 observation wells in the downstream portion of the HRB from 2001 - 2009 were provided by the Institute of Geographic Sciences and Natural Resources Research, Chinese Academy of Sciences and the Ejin Banner Water Affairs Bureau.

\subsection{Analysis Methods}

The greenness rate of change (GRC) is defined as the slope of the least-squares line fitting the inter-annual variability of the seasonally integrated normalized difference vegetation index (SINDVI) values over a specific time period (Stow et al. 2003). The SINDVI is defined as the sum of the NDVI values for a pixel across all time intervals of the maximum value composite (MVC) for which the NDVI exceeds a critical value (commonly NDVI $>0.1$ ).

Similarly, a trend line can be calculated for a certain period and a respective pixel using the linear regression of one variable. The slope of the linear time trend can be calculated using OLS (ordinary least squares) estimation and the total increase (or decrease) during the study period can be estimated based on the slope and years (Ma and Veroustraete 2006a).

\section{RESULTS AND DISCUSSIONS}

\subsection{Changes in Vegetation Cover}

The $8 \mathrm{~km}$ time series PAL AVHRR NDVI data were used to analyze the vegetation changes in the HRB from 1982 - 2001. Most of the vegetated regions experienced decreasing vegetation cover. Increases in vegetation occurred primarily in the mid-basin oasis, whereas decreases in vegetation were mainly observed in the mountainous regions and the Alxa natural oasis region in the HRB (Ma and Veroustraete 2006a).

The VGT NDVI data were then used to monitor the vegetation changes for 2001 - 2010. Patterns of widely increasing vegetation cover during the last ten years are presented in the middle and down streams of the HRB (Fig. 1), but some regions have experienced decreasing vegetation cover. In the middle stream of the HRB the regions of decreasing vegetation are distributed along the main stem or ecotone in Linze County and Gaotai County. In the HRB downstream stream the regions of decreasing vegetation are distributed mainly in the ecotone of the natural oasis.

According to the above analysis a significant shift in the changes in vegetation between the early period, 20 years ago, and the later period, the more recent ten years. The later period represents only the implementation phase of the Comprehensive Control Projects in the HRB. Therefore, the increases in vegetation cover may be completely attributed to the functions of the control projects. But in fact they are likely also determined by various other factors.

\subsection{Precipitation and Runoff Changes}

Figure 2 shows the total annual precipitation for 2001 - 2010 in the mountainous regions, in which there is a clear rapidly increasing trend. In addition, the vegetation cover appears to have generally increased during the same period. The vegetation cover is highly correlated $(r=0.687)$ with precipitation when the value for 2003 is excluded. There is a similar trend in the temperature, which has a similar correlation with vegetation cover, with a correlation coefficient (r) of 0.623. Therefore, the joint effects of precipitation and temperature may have resulted in changes in the natural vegetation cover in the mountainous regions.

The upstream mountainous regions are the water resources for the entire river basin. The runoff from the mountains is consumed in the middle and downstream reaches. The amount of precipitation in the mountainous regions results directly in the runoff from the mountains. There is also

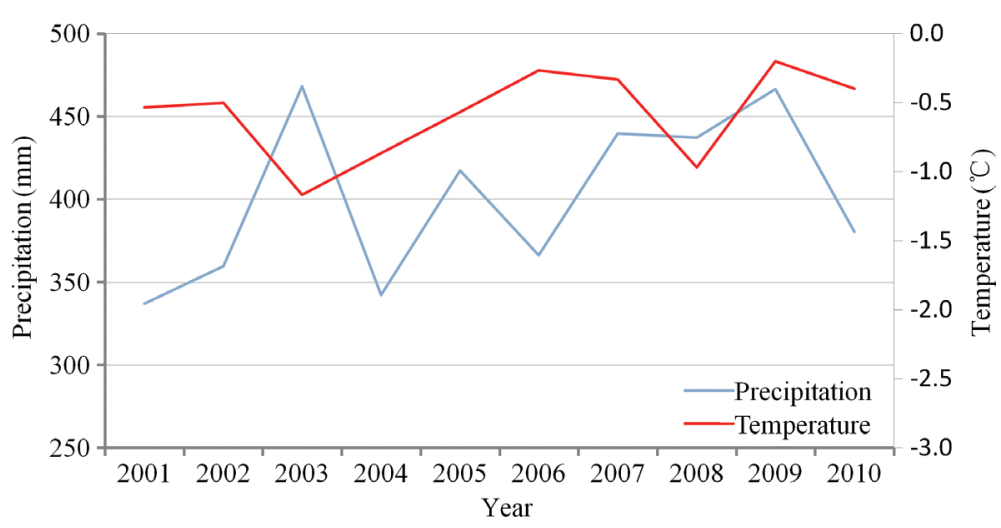

Fig. 2. Total annual precipitation and annual average temperature in the mountainous regions in the Heihe River Basin (HRB) from 2001 - 2010. 
a clear, rapidly increasing trend in the runoff observed at the Yingluoxia Hydrological Station (Fig. 3). The correlation between the precipitation and runoff in the mountains can have a correlation coefficient (r) as high as 0.882 (Table 1).

The runoff at Yingluoxia Station has been high from 2005 through the present, with eight consecutive years with runoff at that station greater than the multi-year average annual runoff of $15.9 \times 10^{8} \mathrm{~m}^{3}$ in the main stem of the Heihe River. As a direct result of this increased runoff, more water has been available in the middle and downstream of the HRB. The availability of water is one of the most important driving factors of vegetation cover change. The high availability of water has resulted in the observed increases in vegetation cover. The amount of water from the main stem used in the middle reaches of the HRB (the water usage amount in the middle or WUAM) can be calculated by subtracting the runoff at Zhengyixia Station from the runoff at Yingluoxia Station. The amount of water from the main stem used in the downstream portion of the HRB (the water usage amount downstream or WUAD) can be directly quantified from the runoff at the Zhengyixia Station. The correlation between the WUAM and the SINDVI from $2001-2010$ exhibits a correlation coefficient (r) as high as 0.504 , indicating that the WUAM causes the increases in vegetation cover to some extent because of the increased quantity and frequency of irrigation for artificial vegetation (Table 1).

In contrast, there is low-level positive correlation between the WUAD and SINDVI values in the downstream HRB from 2001 - 2010, with a correlation coefficient (r) of only 0.274 (Table 2). On the contrary, the relationship between the SINDVI values and the WUAD from previous years was calculated to analyze a possible lag effect (Table 2). The correlation coefficients indicate that there is a one year lag time between the SINDVI and WUAD. It is because the downstream land cover types are primarily natural vegetation, such as Populus euphratica and Tamarix chinensis. The status of this natural vegetation depends primarily on the groundwater table rather than on the irrigation amounts and frequencies. The WUAD normally recharges the groundwater with an extremely long and slow process. That is, movement from surface water to groundwater occurs over longer time spans and thus the surface water does not affect the

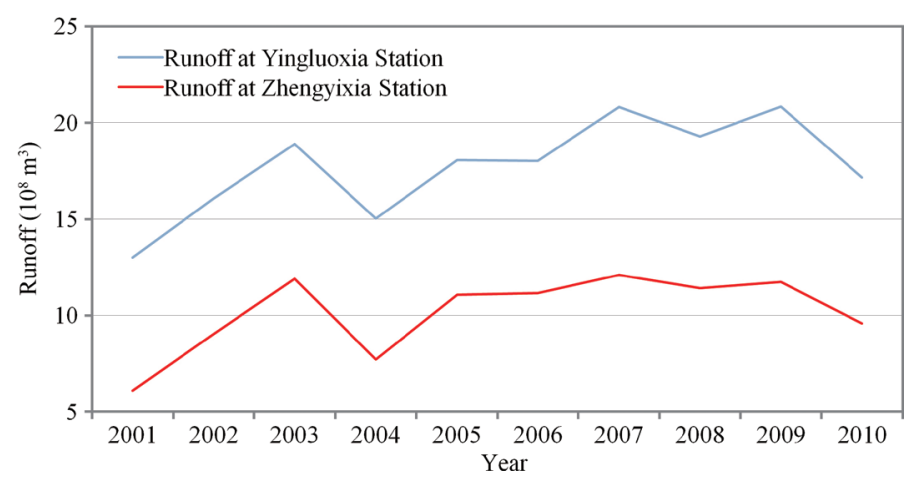

Fig. 3. Annual runoff in the HRB from $2001-2010$.

Table 1. Correlation coefficients among the different indexes in upstream, middle stream and down stream.

\begin{tabular}{ccccc}
\hline Regions & Factors & $\mathbf{T}$ & $\mathbf{P}$ & Water usage amount \\
\hline \multirow{2}{*}{ Upstream } & SINDVI & 0.527 & 0.301 & \\
& Runoff & 0.149 & 0.882 & \\
\cline { 1 - 1 } Middle Stream & SINDVI & 0.439 & 0.766 & 0.504 \\
\hdashline Downstream & SINDVI & -0.171 & 0.018 & 0.274 \\
\hline
\end{tabular}

Table 2. Correlation coefficients between the SINDVI values and the water usage amount downstream (WUAD).

\begin{tabular}{ccccc}
\hline & \multirow{2}{*}{ Same year } & \multicolumn{3}{c}{ Previous years } \\
\cline { 3 - 5 } & & One year & Two Years & Three Years \\
\hline $\mathrm{r}$ & 0.274 & 0.705 & 0.362 & 0.235 \\
\hline
\end{tabular}


natural vegetation directly. Furthermore, the WUAD mainly happens in the second half year, which can occupy more than $63 \%$ of the total surface water amount. In addition, a month is required for the surface water from Zhengyixia hydrological section to move downstream. Therefore, the above multiple factors result in the WUAD lag effect on the downstream vegetation cover.

\subsection{Land Use Change}

In both the middle and downstream portions of the HRB agriculture has experienced the greatest recent increase among the land use types. In the middle stream, the increased farmlands are distributed primarily at the edge of the oasis and are transformed from bare desert land (Fig. 4). Some wetlands are also occupied by newly reclaimed farmland. In the downstream area the newly reclaimed farmlands are distributed primarily in the middle of the natural oasis and are interlaced with Populus euphratica forests and brush forests, which further fragment the natural oasis (Fig. 5).
The reclamation of farmlands from sparse vegetation or bare land can clearly increase the vegetation cover, which may provide a false impression of increasing vegetation cover (Figs. 4 and 5), suggesting that human production activities, rather than increases in the natural vegetation cover, may be the cause of the increased vegetation cover. These agricultural activities are likely to consume more water resources than would natural vegetation.

\subsection{The Groundwater Level}

Because the surface water resources for irrigation are limited in the middle reaches of the HRB, the amount of groundwater mining would obviously also increase. The downstream farmland primarily depends on groundwater mining. The expanded farmlands are rapidly increasing the mining of downstream groundwater, which affects the groundwater levels and, in turn, the natural vegetation growth.

In the middle reaches of the HRB the groundwater level has decreased only slightly, although there are great

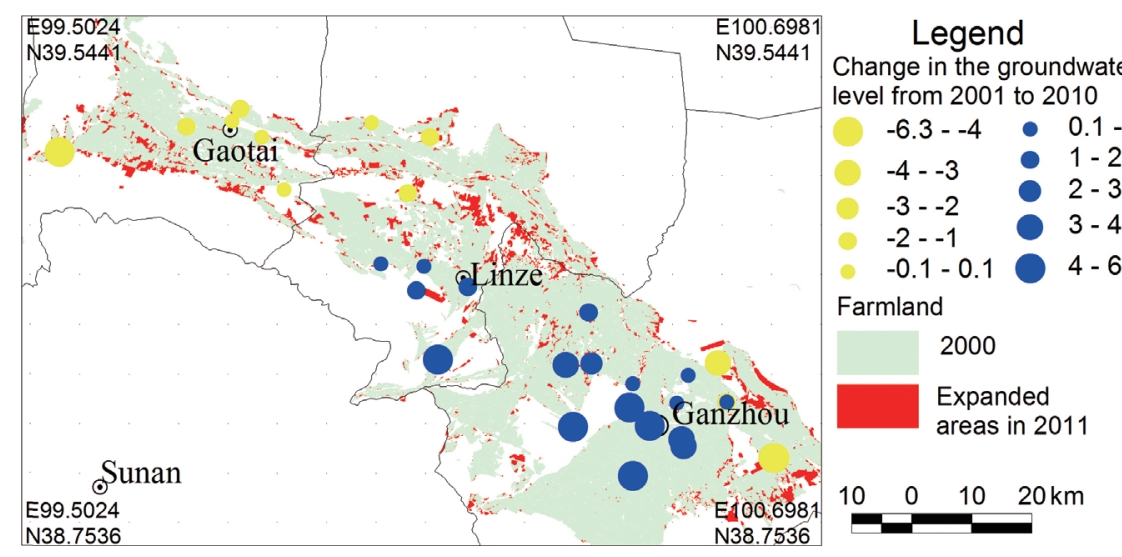

Fig. 4. Changes in farmland area and groundwater level in the middle reaches of the HRB.

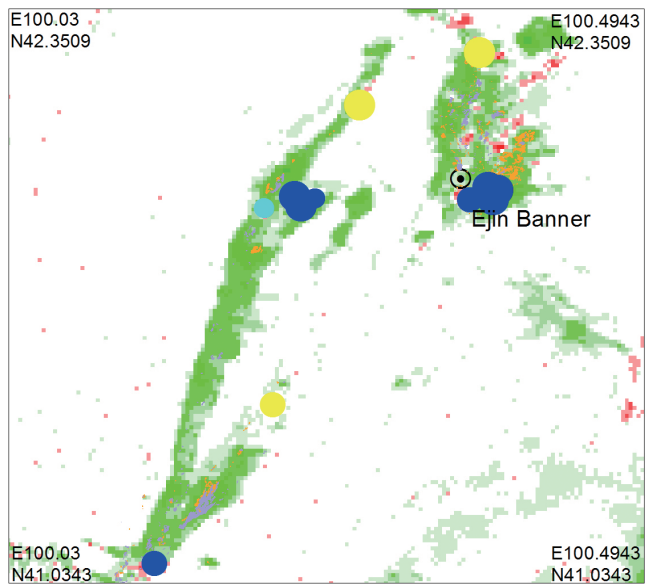

\section{Legend}

Change in the groundwater level from 2001 to 2009

$-1-0.5 \bigcirc 0.1-0.3$

$-0.5--0.1 \bigcirc 0.3-0.5$

$-0.1-0.1 \bigcirc 0.5-0.8$

Change in the SINSVI

from 2001 to 2010

from 2001 to $2010 \square 0.1-0.5$

$-1.5--1 \square 0.5-1$

$-1--0.5 \quad 1-2$

$-0.5--0.1 \square 2-5$

$-0.1-0.1 \square-10.7$

Farmland

2000

Expanded areas in 2011

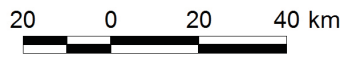

Fig. 5. The seasonally integrated normalized difference vegetation index (SINDVI) and groundwater level change in the downstream reaches of the HRB. 
differences in the change spatial distribution across the HRB (Fig. 6). The groundwater levels are generally increasing in Ganzhou District, except in two wells in the northeast regions. In contrast, the groundwater levels are generally decreasing in Linze County and Gaotai County. The regions with increasing groundwater levels have similar characteristics: the farmlands around these wells have not obviously expanded (Fig. 6), and the SINDVI values are increasing.

The situations in regions with decreasing groundwater levels are complex. Figure 4 shows that the regions with decreasing groundwater levels are generally close to newly cultivated farmlands in the middle portion of the HRB, which depend primarily on groundwater for irrigation, resulting in rapid decreases in groundwater levels. Other wells are located in regions with decreasing SINDVI values, which are primarily distributed in the ecotones or along the main stem of the Heihe River (Fig. 6). These regions are primarily covered with natural vegetation which depends mainly on groundwater. Thus, the decreasing groundwater levels result in natural vegetation degradation, as confirmed by monitoring by local governments.

The spatial distribution of the changes in groundwater levels in the downstream reaches of the HRB is also highly variable (Fig. 5). The regions with increasing groundwater levels are distributed primarily in the core natural oasis, where the regions with increasing SINDVI values are also located. The regions with decreasing groundwater levels are primarily distributed along the edges of the natural oasis, in the ecotone, where the regions with decreasing SINDVI values are also located. As stated above, the vegetation covers depend mainly on the ground water level in the downstream HRB. Therefore the correlation coefficient between the groundwater level and the average SINDVI of the $3 \times 3$ pixels around the groundwater well was calculated for each well (Table 3). The results indicate that most of the wells with increasing ground water levels have a positive correction. There is an obvious positive correction between the average groundwater levels with the average SINDVI values in the downstream reaches of the HRB. A one-year lag effect can also be found.

\subsection{Potential Risks to the Ecological and Hydrological Processes in the HRB}

According to the above analysis the potential risks to the ecological and hydrological processes require further attention from the local HRB managers. The continuous and obvious increase in runoff in the mountains is an important

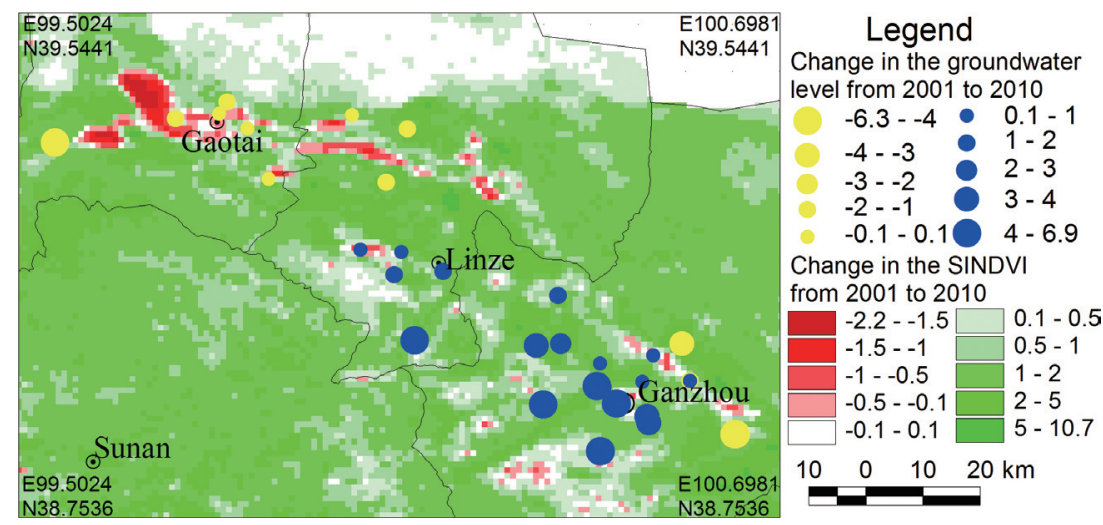

Fig. 6. The SINDVI and groundwater level change in the middle reaches of the HRB.

Table 3. Correlation coefficients between the SINDVI values and the WUAD.

\begin{tabular}{c|ccccccccccccc}
\hline & $\mathbf{1}$ & $\mathbf{2}$ & $\mathbf{3}$ & $\mathbf{4}$ & $\mathbf{5}$ & $\mathbf{6}$ & $\mathbf{7}$ & $\mathbf{8}$ & $\mathbf{9}$ & $\mathbf{1 0}$ & $\mathbf{1 1}$ & $\mathbf{1 2}$ & Total \\
\hline Longitude & 100.36 & 101.11 & 100.69 & 100.73 & 100.70 & 100.62 & 101.15 & 101.09 & 101.14 & 100.64 & 101.13 & 100.84 & \\
Latitude & 41.08 & 42.25 & 41.92 & 41.92 & 41.90 & 41.89 & 41.93 & 41.91 & 41.91 & 41.44 & 41.94 & 42.13 \\
Change_GW & 0.39 & -0.70 & 0.74 & 0.25 & 0.74 & 0.14 & 0.61 & 0.40 & 0.78 & -0.11 & 0.60 & -1.00 & \\
r_same & 0.70 & -0.55 & 0.33 & -0.41 & 0.23 & 0.06 & 0.69 & 0.69 & 0.77 & 0.52 & 0.71 & -0.15 & 0.64 \\
r_pre one & 0.46 & -0.79 & 0.37 & -0.48 & 0.22 & 0.69 & 0.51 & 0.68 & 0.71 & -0.23 & 0.84 & -0.69 & 0.72 \\
r_pre two & 0.47 & -0.65 & 0.47 & 0.21 & 0.33 & 0.41 & 0.68 & -0.14 & 0.34 & -0.65 & 0.44 & -0.82 & 0.20 \\
\hline
\end{tabular}

Note: Change_GW: change of the ground water level from 2001 - 2009; $r$ same: correlation coefficient between the SINDVI and groundwater

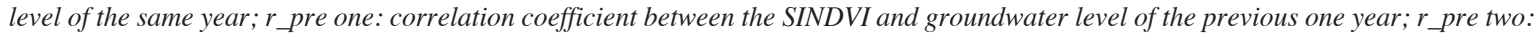
correlation coefficient between the SINDVI and groundwater level of the previous two year. 
cause of the increases in vegetation cover. The expanding farmland regions in the middle and downstream areas may cause severe challenges for the local governments in future years with continuously low flow. There are significant areas of decreasing vegetation along the main river and in the oasis ecotone in the middle reaches of the HRB, which are caused by ground water over exploitation. Therefore, groundwater use must be strongly controlled in these regions. Groundwater recharge is very unevenly distributed in the downstream portion of the HRB. Effective measures for managing the widely distributed areas with degraded vegetation cover along the oasis edges should be adopted by the local government.

\section{CONCLUSIONS AND DISCUSSION}

A time-series remote sensing data set was effectively used to monitor the changes in vegetation cover in the HRB. There are widely distributed areas with increasing vegetation cover throughout the river basin. The interaction of increasing precipitation and temperature result in increasing vegetation cover in the mountainous regions. The obvious and continuous increase in runoff in the mountains is an important cause of the increasing vegetation cover in the middle and downstream portions of the HRB. Some areas with local decreases in vegetation cover are covered primarily with natural vegetation, which greatly depends on the availability of groundwater resources, and thus, the loss of vegetation is due primarily to the decreasing groundwater levels.

There are big differences in the relationships among the SINDVI derived from satellite observations with several hydrological variables in the different HRB regions. This paper provides a summary analysis of the entire river basin scale, which can give us an overview of the spatial differences in driving factors for the changes in vegetation cover. Special analysis and discussion on the ecological and hydrological effect of the changes in vegetation cover need to be processed for the upper stream, middle stream, and downstream.

Acknowledgements This work was supported by the by the Chinese State Key Basic Research Project (grant number: 2009CB421305) and the Knowledge Innovation Program of the Chinese Academy of Sciences (grant number: KZCX2-EW-312). Some workmen from the Zhangye Water Conservancy Bureau joined the field investigation land use classification work. The authors would also like to thank the Anonymous Reviewers for their insightful comments.

\section{REFERENCES}

Chang, Y., D. Bao, and Y. Bao, 2011: Satellite monitoring of the ecological environment recovery effect in the Heihe River downstream region for the last 11 years. Procedia Environ. Sci., 10, 2385-2392, doi: 10.1016/j. proenv.2011.09.371. [Link]

Huang, G., 2013: Would use of contaminated water for irrigation lead to more accumulation of nitrate in crops? Environ.Pollut., 2, 1-9, doi: 10.5539/ep.v2n4p1. [Link]

Jia, L., H. Shang, G. Hu, and M. Menenti, 2011: Phenological response of vegetation to upstream river flow in the Heihe Rive basin by time series analysis of MODIS data. Hydrol. Earth Syst. Sci., 15, 1047-1064, doi: 10.5194/hess-15-1047-2011. [Link]

Li, X., L. Lu, G. Cheng, and H. Xiao, 2001: Quantifying landscape structure of the Heihe River Basin, northwest China using FRAGSTATS. J. Arid Environ., 48, 521-535, doi: 10.1006/jare.2000.0715. [Link]

Lu, L., X. Li, and G. Cheng, 2003: Landscape evolution in the middle Heihe River Basin of north-west China during the last decade. J. Arid Environ., 53, 395-408, doi: 10.1006/jare.2002.1032. [Link]

Ma, M. and F. Veroustraete, 2006a: Interannual variability of vegetation cover in the Chinese Heihe River Basin and its relation to meteorological parameters. Int. J. Remote Sens., 27, 3473-3486, doi: 10.1080/01431160600593031. [Link]

Ma, M. and F. Veroustraete, 2006b: Reconstructing pathfinder AVHRR land NDVI time-series data for the Northwest of China. Adv. Space Res., 37, 835-840, doi: 10.1016/j.asr.2005.08.037. [Link]

Maisongrande, P., B. Duchemin, and G. Dedieu, 2004: VEGETATION/SPOT: An operational mission for the Earth monitoring; presentation of new standard products. Int. J. Remote Sens., 25, 9-14, doi: 10.1080/ 0143116031000115265. [Link]

Stow, D., S. Daeschner, A. Hope, D. Douglas, A. Petersen, R. Myneni, L. Zhou, and W. Oechel, 2003: Variability of the seasonally integrated normalized difference vegetation index across the north slope of Alaska in the 1990s. Int. J. Remote Sens., 24, 1111-1117, doi: 10.1080/0143116021000020144. [Link]

Wang, P., Y. Zhang, J. Yu, G. Fu, and F. Ao, 2011: Vegetation dynamics induced by groundwater fluctuations in the lower Heihe River Basin, northwestern China. $J$. Plant Ecol., 4, 77-90, doi: 10.1093/jpe/rtr002. [Link]

Wang, Q., G. Hu, and H. Chen, 2008: Analysis on benefit of recent integrated control projects for Heihe River Basin in Zhangye city. J. Desert Res., 28, 498-503. (in Chinese)

$\mathrm{Wu}, \mathrm{J} ., 2011$ : The effect of ecological management in the upper reaches of Heihe River. Acta Ecol. Sin., 31, 1-7, doi: 10.1016/j.chnaes.2010.11.001. [Link]

Zhou, J., X. Li, G. Wang, and J. Zhao, 2009: The spatiotemporal variation analysis of groundwater and response to land-use change in the middle reaches of the Heihe River basin. J. Nat. Resour., 24, 498-506, doi: 10.11849/zrzyxb.2009.03.015. (in Chinese) [Link] 